\title{
Characterization of Hemophilic and Related Bacteria by Their Respiratory Quinones and Cytochromes
}

\begin{abstract}
R. HOLLÄNDER AND W. MANNHEIM
Hygiene-Institut der Philipps-Universität, Marburg/Lahn, Federal Republic of Germany

Nineteen strains of gram-negative organisms representing 10 Haemophilus species, Eikenella corrodens, and the so-called Haemophilus vaginalis were investigated for cytochromes and respiratory quinones. Phenotypical variation of cytochrome and quinone contents was checked using cells grown with oxygen and fumarate as alternative electron acceptors. The cytochromes were detected by difference spectra of briefly sonicated cells at room temperature, and the quinones were determined in lipid extracts by difference spectrophotometry and partly by thin-layer chromatography. In contrast to other conventional groups of chemo-organotrophic, gram-negative bacteria that have been found to be highly homogeneous with respect to the respiratory chain components, the organisms investigated here may be divided into three categories by their respiratory quinones, namely (i) bacteria containing desmethylmenaquinone as sole respiratory quinone- $H$. influenzae, $H$. aegyptius, $H$. paraphrophilus, $H$. parahaemolyticus, $H$. parainfluenzae (in part), (ii) bacteria containing both ubiquinone and desmethylmenaquinone-H. haemoglobinophilus, $H$. parasuis, $H$. paragallinarum, $H$. parainfluenzae (in part), and (iii) bacteria containing only ubiquinone $-H$. piscium, so-called $H$. vaginalis, and $E$. corrodens. The data presented may contribute to further characterization, independent of growth factor requirements, of the taxonomic entities investigated. In the absence of information on deoxyribonucleic acid relatedness between the organisms under study, a provisional reclassification of Haemophilus and related taxa on the basis of respiratory quinones is discussed.
\end{abstract}

Requirements for protoheme (or protoporphyrin IX) and/or nicotinamide adenine dinucleotide (NAD) as growth factors have been used as the essential criteria for classification of the chemo-organotrophic, aerobic, nonmotile, gram-negative bacteria of the genus Haemophilus (19). However, there are a number of examples that heme and/or NAD-requiring bacteria may develop from unrelated parental forms, e.g., Micrococcus pyogenes (12), Escherichia coli (4), and Bacteroides ruminicola (7). Therefore, the lack of enzymes for the synthesis of heme or pyridine nucleotides is not itself an adequate basis for the classification of haemophiles.

Besides growth factor and complex substrate requirements, a common feature of all Haemophilus species hitherto described appears to be vertebrate parasitism. If they were a phylogenetically homogeneous group, one would have to expect a high degree of phenotypic similarity of the group members in many other respects.

We investigated the question of such similarity in the composition of the respiratory chain. The data presented here indicate that, accord- ing to their respiratory quinones, there are several different groups among the so-called haemophilic bacteria. These findings may contribute to a new definition of Haemophilus and of contiguous groups of organisms.

\section{MATERIALS AND METHODS}

Microorganisms. The bacterial cultures used are listed in Table 1. Before use, collection cultures were examined for microscopic appearance, Gram reaction, colonial morphology, growth factor requirements, and biochemical activities.

Media and cultivation. Proteose peptone medium (27) was the complex medium base used for all organisms except $H$. piscium, which was cultivated in fish peptone medium (medium no. 69, ATCC catalogue, 1972), and "H. vaginalis," which was grown in liver broth (sliced bovine liver was overlaid with two volumes of meat broth [beef extract. $0.8 \%$; peptone. $1.0 \%$; $\left.\mathrm{NaCi}, 0.3 \% ; \mathrm{Na}_{2} \mathrm{HPO}_{4}, \mathrm{U} .2 \% \mathrm{wt} / \mathrm{vol}\right]$ and autoclaved at $121 \mathrm{C}$ for $15 \mathrm{~min}$. (Beef extract and peptone were from Merck, Darmstadt, Germany.) The media were sterilized by filtration and supplemented before use with NAD $(5.0 \mu \mathrm{g} / \mathrm{ml})$, hemin (hemin chloride [Fluka, Buchs, Switzerland] dissolved in triethanol amine; $0.5 \mu \mathrm{g} / \mathrm{ml}$ ), and, where indicated, with disodium fumarate (Fluka; $0.8 \% \mathrm{wt} / \mathrm{vol}$ ), from 100-timesconcentrated stock solutions kept at $4 \mathrm{C}$. 
TABLE 1. Bacterial cultures investigated

\begin{tabular}{|c|c|c|}
\hline Species & Strain & $\begin{array}{l}\text { Source of } \\
\text { supply/collec- } \\
\text { tion no. }{ }^{a}\end{array}$ \\
\hline $\begin{array}{l}\text { Haemophilus } \\
\text { influenzae }\end{array}$ & RAMC 18 Bensted & NCTC 4560 \\
\hline H. influenzae & & HIM $412-7$ \\
\hline$H$. influenzae & 641 Pittman & NCTC 8467 \\
\hline H. parainfluenzae & & HIM 412-6 \\
\hline H. parainfluenzae & & HIM $170-1$ \\
\hline$H$. parainfluenzae & 1 Fleming & NCTC 4101 \\
\hline H.parainfluenzae & 429 Pittman & ATCC 7901 \\
\hline H. parainfluenzae & Bossy No. 7 Leidy & HIM $449-8$ \\
\hline $\begin{array}{l}\text { H. paragallinarum } \\
\text { (5) }\end{array}$ & 6 Lovell & NCTC 3438 \\
\hline $\begin{array}{l}\text { H. haemoglobino- } \\
\text { philus (canis) }\end{array}$ & XIII Friedberger & NCTC 1659 \\
\hline H. parasuis (5) & 1374 Shope & NCTC 4557 \\
\hline H. aegyptius & 180-a Pittman & ATCC 11116 \\
\hline H. aegyptius & Leidy & HIM $450-4$ \\
\hline H.piscium & Snieszko & ATCC 10801 \\
\hline "H. vaginalis" & Dukes 594 & ATCC 14018 \\
\hline H. paraphrophilus & Funagli & NCTC 10557 \\
\hline $\begin{array}{l}\text { H. parahaemolyti- } \\
\text { cus (5) }\end{array}$ & 536 Pittman & NCTC $8479^{\circ}$ \\
\hline $\begin{array}{l}\text { H. paraphrohae- } \\
\text { molyticus }\end{array}$ & L 1 Zinnemann & NCTC 10670 \\
\hline $\begin{array}{l}\text { Eikenella } \\
\quad \text { corrodens }\end{array}$ & 333/54-55 Henriksen & NCTC 10596 \\
\hline
\end{tabular}

${ }^{a}$ NCTC, National Collection of Type Cultures, London, Great Britain; ATCC, The American Type Culture Collection, Rockville, Maryland; HIM, Collection of the HygieneInstitut, Marburg, Germany.

Aerobic cultures were grown in Fernbach flasks (no. 20511 Schott \& Gen., Mainz, Germany) containing $400 \mathrm{ml}$ of medium and aerated by shaking in a rotatory shaker (model G-25, New Brunswick Scientific Co.) at $200 \mathrm{rpm}$. Oxygen-limited cultures were grown statically in Fernbach flasks filled with $2,000 \mathrm{ml}$ of medium containing fumarate as an additional supplement. The incubation temperature was $37 \mathrm{C}$ except for $H$. piscium, which was incubated at $20 \mathrm{C}$. Cells of the early stationary phase were harvested at $20,000 \times$ $g, 0$ to $4 \mathrm{C}$, and washed twice in $0.1 \mathrm{M}$ tris(hydroxymethyllaminomethane-hydrochloride buffer, pH 7.2.

Determination of protein. Protein was determined in sonically treated bacterial suspensions by the biuret method using $\mathrm{KCN}(22)$.

Extraction and determination of quinones. Quinones were extracted by the method of Kröger and Dadák (13) and determined by their characteristic absorption spectra in ethanolic solution, using a recording spectrophotometer (model EPS-3T, Hitachi Ltd., Tokyo). The absorption differences of the reduced minus oxidized quinones at 230 to $300 \mathrm{~nm}$ were recorded $(13,18)$. The quinone spectra were plotted by the methods of White (25) and Kröger and Klingenberg (15).

The amounts of ubiquinone (Q) and desmethylmenaquinone (DMK) were calculated using the difference extinction $\Delta_{\mathbf{e}_{280-289}}=-8.8 \mathrm{mM}^{-1} \times \mathrm{cm}^{-1}(14)$ and $\Delta \epsilon_{246-285}^{\mathrm{DMKK}}=26.7 \mathrm{mM}^{-1} \times \mathrm{cm}^{-1}(25)$.

If both $Q$ and DMK were present in the lipid extract, the amounts of the individual quinones were calculated by the equations of Kröger et al. (14) using the difference extinction coefficients $\Delta \epsilon_{1280-289}^{Q}=-9.6$, $\Delta \epsilon_{1280-290}^{\mathrm{DMK}}=-1.4, \Delta_{2250-255}^{Q}=2.1$ and $\Delta \epsilon_{2250-255}^{\mathrm{DMK}}=20.2$ $\left(\mathrm{m} \mathbf{M}^{-1} \times \mathrm{cm}^{-1}\right)$.

When spectrophotometrically pure naphthoquinone extracts were obtained, the presence of even small quantities of $Q$ was excluded by thin-layer chromatography on kieselgel (Merck, Darmstadt, Germany).

Ethylmethylketone $(15 \% \mathrm{vol} / \mathrm{vol})$ in hexane was used as the solvent system (9). The amount of contaminating $\mathrm{Q}$ was then determined by the method of Lester and Ramasarma (17), sensitive to $1.3 \mathrm{nmol}$ of Q.

Determination of cytochromes. Cytochromes were determined by difference spectrophotometry of turbid suspensions of morphologically intact bacteria (that had been sonically treated briefly to insure uncoupling), using a Diffuse Reflectance Accessory of the EPS-3T spectrophotometer. The characteristic spectral properties of cytochromes of $a a_{3}, a_{1}, d\left(a_{2}\right), b$, and $c$ types were recognized by the difference spectrum of $\mathrm{Na}_{2} \mathrm{~S}_{2} \mathrm{O}_{4}$-reduced minus $\mathrm{H}_{2} \mathrm{O}_{2}$-oxidized samples of a given bacterial suspension recorded from 390 to $650 \mathrm{~nm}$.

Further spectral properties of cytochrome oxidases and, in particular, of cytochrome $o$ were detected by the difference spectrum $\mathrm{Na}_{2} \mathrm{~S}_{2} \mathrm{O}_{4}$-red/CO minus $\mathrm{Na}_{2} \mathrm{~S}_{2} \mathrm{O}_{4}$-red. The $\alpha$-maxima of cytochrome pigments in difference spectra (redox) and the corresponding minima in carbon monoxide spectra were used for their identification and quantitative assay (cf. 2, 21).

Since in most instances molar extinction coefficients of bacterial cytochromes in situ are not known, the amount of cytochrome was only specified as absorption difference per gram of bacterial protein and centimeter of optical pathway, corrected for the amplification effect of the diffuse reflectance equipment. The amplification factor was determined from the absorption spectrum of a known amount of cytochrome $c$ (Fluka, Buchs, Switzerland) added to the reference cuvette and recorded over the red minus red base line with each bacterial suspension.

\section{RESULTS}

The scope of the present investigation was classification of haemophilic bacteria according to phylogenetic variations in composition of the respiratory chain. Since, however, the phenotypical dynamics of bacterial respiratory chain systems have to be taken into consideration, the bacteria were grown with two alternative electron acceptors, oxygen or fumarate, as described above. Fumarate may serve as a terminal acceptor in anaerobic electron transfer in some gram-negative bacteria (cf. 14, 26). With organisms unable to reduce fumarate, however, only oxygen-limited growth could be expected using the unaerated complex culture medium.

The cytochromes and respiratory quinones of cells harvested in the early stationary phase are shown in Table 2. As indicated by the table, 
cytochromes of the $b$ and/or $c$ type, as well as cytochrome $o$, are common to all organisms examined. In addition, cytochromes $a$ and/or $d$ were detected in some strains. The amount of cytochromes synthesized may vary considerably among different strains and among derivatives of a given strain according to culture conditions, For example, strains of the species $H$. influenzae and $H$. aegyptius (except strain 641 Pittman) produced only a few percent of the maximum amounts of cytochromes found in $H$. parainfluenzae cultures.

Table 2 further indicates that the bacteria investigated contain either $\mathrm{Q}$ or DMK, or both, respiratory chain components in varying proportions. Strains producing both $\mathrm{Q}$ and DMK ( $H$. parainfluenzae strains HIM 412-6 and 1 Fleming, $H$. haemoglobinophilus, $H$. parasuis, $H$. paragallinarum) show the tendency to reduce $\mathrm{Q}$ in favor of $\mathrm{DMK}$ when cultivated anaerobically in the presence of fumarate. Furthermore, in most of the strains producing DMK $(H$. influenzae, $H$. parainfluenzae strains HIM 170-1, and Bossy No. 7 Leidy, H. aegyptius, $H$. paraphrophilus, $H$. parahaemolyticus, $H$. paraphrohaemolyticus) the growth yields of oxygen-limited cultures are increased by fumarate whereas growth of strains containing only $\mathbf{Q}$ ( $H$. piscium, " $H$. vaginalis," Eikenella corrodens) remains unaffected.

H. parainfluenzae strain 429 Pittman could not be cultivated anaerobically; however, when grown aerobically in the presence of fumarate, this organism contained, in addition to $\mathrm{Q}$, respectively small amounts of a redox active quinone that has not yet been identified but is considered to be a naphthoquinone derivative similar to DMK on the basis of spectral properties and $R_{f}$ values.

\section{DISCUSSION}

The data presented suggest that, in addition to aerobic respiration, the majority of the organisms investigated possess a DMK-mediated anaerobic fumarate respiration pathway, whereas other Haemophilus strains that have been found to produce only $\mathrm{Q}$ appear to be metabolically related to nonfermentative groups of bacteria.

The taxonomic significance of these findings should be considered in relation to the variability of respiratory chain components in well established groups in order to evaluate this type of criteria, rarely used to date in bacterial classification. As for the distribution of cytochromes, the bacterial strains examined here are qualitatively similar. However, their hetero- geneity with respect to the terpenoid quinones is unusual, as other generic groups of bacteria are highly invariable in this respect. As a rule, chemo-organotrophic gram-negative Eubacteriales and Pseudomonadales that utilize organic compounds only by oxidation with oxygen or nitrates as electron acceptors contain $Q$ as the only quinone component of the respiratory chain system $(6,24 ; \mathrm{E}$. Callies, manuscript in preparation).

In contrast, many facultatively aerobic gram-negative bacteria which produce acid from carbohydrates in the absence of oxygen or nitrate are able to produce two different respiratory quinones, namely, $\mathrm{Q}$ in aerobic respiration, and a naphthoquinone, predominantly menaquinone (MK), in anaerobic respiration with fumarate as electron acceptor. This holds true for the Enterobacteriaceae (14, 23, 24; R. Jediss, M.D. thesis, Philipps University, Marburg, W. Germany, 1973), Yersinia, Vibrio, and Aero. monas (23; R. Zabel, M.D. thesis, Philipps University, 'Marburg, W. Germany, 1974), whereas other groups of facultatively or strictly anaerobic gram-negative bacteria may contain only MK.

MK is also the respiratory quinone of aerobic and facultatively anaerobic gram-positive bacteria (cf. 6, 11, 16). Among the fermentative Brucellaceae, the leading Pasteurella and Actinobacillus species produce both $\mathrm{Q}$ and DMK (R. Zabel, Ph.D. thesis), a quinone first detected in Streptococcus faecalis (3) and in a strain of Haemophilus parainfluenzae (18). DMK may be accumulated as a precursor or by-product in MK biosynthesis $(23,24)$.

The organisms hitherto ascribed to Haemophilus may be subdivided, according to their respiratory quinones, into (i) bacteria that contain DMK alone, (ii) bacteria containing both $\mathrm{Q}$ and DMK, and (iii) bacteria containing only $\mathrm{Q}$. This statement leads to the supposition that the genus Haemophilus in its present composition is probably not a natural group, and even some of the conventional Haemophilus species appear to be heterogeneous. However, we do not rule out that, with organisms in which the ability of synthesizing several respiratory chain components varies so greatly, variation in biosynthesis of the respiratory quinones might be possible as well. Therefore, the following tentative reclassification of Haemophilus and related bacteria, on the basis of the respiratory quinones, deserves further confirmation, in particular, by investigation of DNA relatedness.

Genus Haemophilus sensu strictiori (s.s.). The type species of Haemophilus, H. influen$z a e$, produces DMK as sole respiratory quinone. 


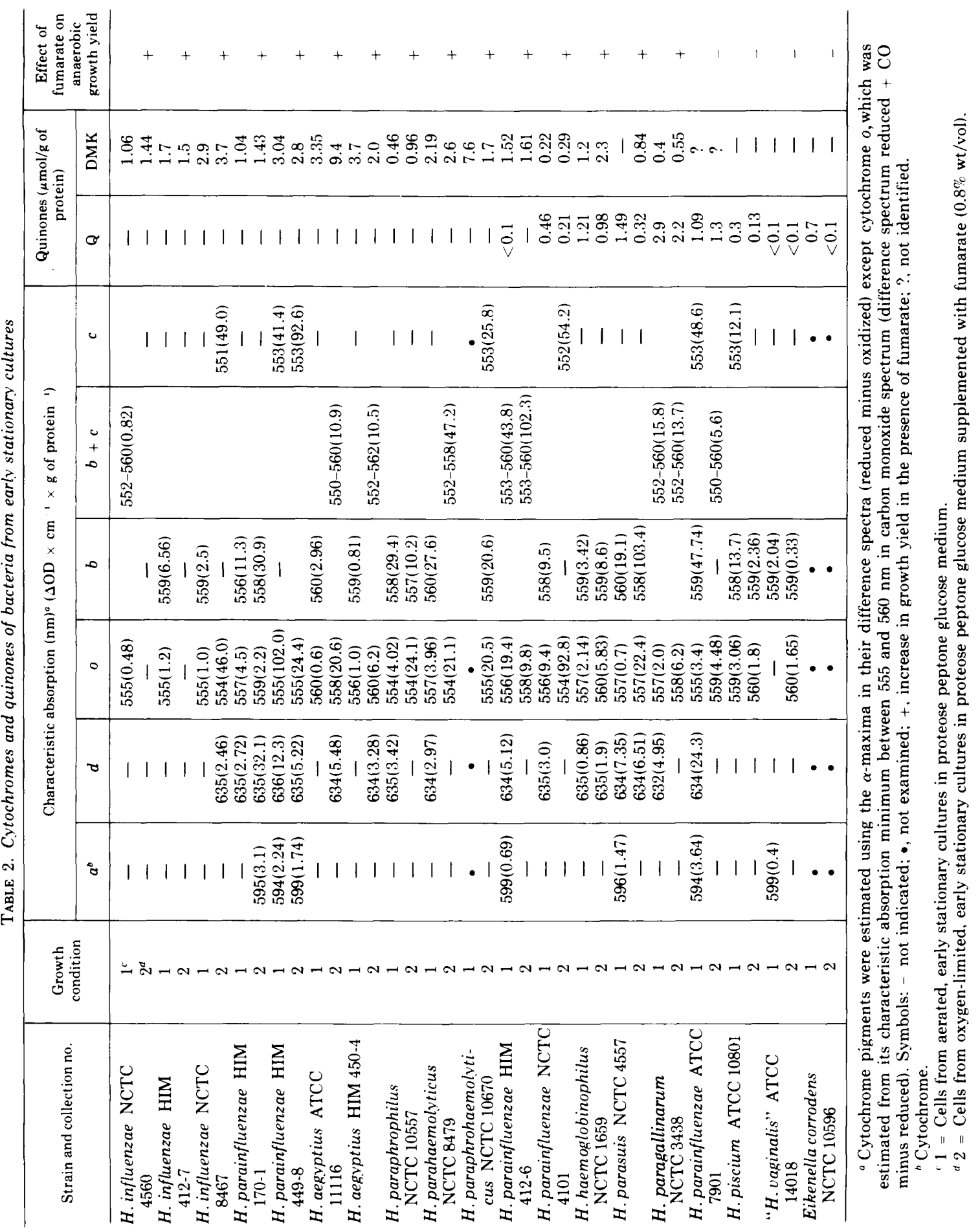


Besides $H$. influenzae, the $H$. aegyptius, $H$. paraphrophilus, $H$. parahaemolyticus, and $H$. paraphrohaemolyticus strains investigated, as well as two $H$. parainfluenzae strains (HIM 170-1 and Bossy no. 7 Leidy), exhibit the same property. Moreover, if $\mathrm{V}$ and $\mathrm{X}$ factor requirements are not considered as taxonomic characters, Haemophilus aphrophilus and Pasteurella pneumotropica, which both contain only DMK (30), will fit into this group, which then could be redefined as follows: small, nonmotile, coccoid to thread-forming, gram-negative rods that are obligate vertebrate parasites, contain DMK as sole respiratory quinone, and require highly complex media. Species differentiation within this genus Haemophilus sensu strictiori adheres to most of the traditional criteria. Fermentation of carbohydrates is typical but not an obligatory character of this genus, since nonfermenting strains of $H$. aegyptius do occur (e. g., strain 180a Pittman).

Fermentative bacteria to be eliminated from Haemophilus s.s. The organisms producing both DMK and Q, $H$. paragallinarum, $H$. haemoglobinophilus, $H$. parasuis, and $H$. parainfluenzae (strains 1 Fleming and HIM 412-6), should be placed close to Actinobacillus lignieresii, Actinobacillus equuli, Pasteurella haemolytica, and Pasteurella multocida (cf. R. Zebel, M.D. thesis).

The position of $H$. parainfluenzae strain 429 Pittman will remain uncertain until the nature of its second quinone is elucidated.

Nonfermentative bacteria to be eliminated from Haemophilus s.s. Those "haemophilic" bacteria that contain $Q$ as sole respiratory quinone, namely $H$. piscium and " $H$. vaginal$i s$," are probably not a homogeneous group of organisms; they should be transferred to already existing or new taxa of gram-negative bacteria. Eikenella corrodens (Bacteroides corrodens) (cf. 10) may be related to some of these organisms because of similar growth requirements and $\mathrm{Q}$ content.

"Haemophilus vaginalis" Gardner and Dukes 1955 , originally described as a gram-negative organism, was removed from the genus Haemophilus by the majority of the more recent investigators mainly because its Gram reaction depends on the growth medium used $(1,20,28$, and others). The data presented here, however, although eliminating strain Dukes 594 from Haemophilus, do not support the view that " $H$. vaginalis" could be related to gram-positive taxa; the presence of $Q$ rather confirms the statement of Criswell et al. (8) that strain 594 is a true gram-negative organism since gram-positive bacteria do not form $\mathrm{Q}$ as far as is known.

\section{ACKNOWLEDGMENT}

We are indebted to K. S. Zinnemann, Leeds, for encouragement and helpful criticism.

\section{REPRINT REQUESTS}

Address reprint requests to: Dr. W. Mannheim or Dr. R. Holländer, Hygiene-Institut, Philipps University, 355 Marburg/Lahn, D. Pilgrimstein 2, West Germany.

\section{LITERATURE CITED}

1. Amies, C. R., and M. Garabedian. 1963. The bacteriology of human vaginitis. Can. J. Public Health 54:50.

2. Bartsch, R. G. 1968. Bacterial cytochromes. Annu. Rev. Microbiol. 22:181-200.

3. Baum, R. H., and M. I. Dolin. 1963. Isolation of a new naphthoquinone from Streptococcus faecalis $10 \mathrm{C} \mathrm{1.J.}$ Biol. Chem. 238:4109-4111.

4. Beljanski, M. 1955 . Isolement des mutants d'Escherichia coli streptomycinrésistants de'pourvus d'enzymes respiratoires. Action de l'hémine sur la formation de ces enzymes chez le mutant $\mathrm{H}_{7}$. C. R. Acad. Sci. Paris 240:374-377.

5. Biberstein, E. L., and K. Zinnemann. 1971. Report (1966-1970) of the Subcommittee on the Taxonomy of Haemophilus to the International Committee on Nomenclature of Bacteria. Int. J. Syst. Bacteriol. 21:133-134

6. Bishop, D. W., K. P. Pandya, and H. K. King. 1962 Ubiquinone and Vitamin $\mathrm{K}$ in bacteria. Biochem. J. 83:606-614.

7. Caldwell, D. R., D. C. White, M. P. Bryant, and R. N. Doetsch. 1965. Specificity of the heme requirement for growth of Bacteroides ruminicola. J. Bacteriol. 90:1645-1654.

8. Criswell, B. S., J. H. Marston, W. A. Stenback, S. H. Black, and H. L. Gardner. 1971. Haemophilus vaginalis 594, a Gram-negative organism? Can. J. Microbiol. 17:865-869.

9. Dunphy, P. J., P. G. Phillips, and A. F. Brodie. 1971. Separation and identification of menaquinones from microorganisms. J. Lipid Res. 12:442-449.

10. Jackson, F. L., and Y. E. Goodman. 1972. Transfer of the facultatively anaerobic organism Bacteroides corrodens Eiken to a new genus Eikenella. Int. J. Syst. Bacteriol. 22:73-77.

11. Jacobsen, B. K., and H. Dam. 1960. Vitamin K in bacteria. Biochim. Biophys. Acta 40:211-216.

12. Jensen, J., and E. Thofern. 1953. Chlorhämin (Ferroporphyrinchlorid) als Bakterienwuchsstoff. II. Z. Naturforsch. 8b:599-603.

13. Kröger, A., and V. Dadák. 1969. On the role of quinones in bacterial electron transport. The respiratory system of Bacillus megaterium. Eur. J. Biochem. 11:328-340.

14. Kröger, A., V. Dadák, M. Klingenberg, and F. Diemer. 1971. On the role of quinones in bacterial electron transport. Differential roles of ubiquinone and menaquinone in Proteus rettgeri. Eur. J. Biochem. 21:322-333.

15. Kröger, A., and M. Klingenberg. 1970. Quinones and nicotinamide nucleotides associated with electron transfer. Vitam. Horm. 28:533-574.

16. Lester, R. L., and F. L. Crane. 1959. The natural occurrence of coenzyme $Q$ and related compounds. J. Biol. Chem. 234:2169-2173.

17. Lester, R. L., and T. Ramasarma. 1959. Chromatography of the coenzyme $Q$ family of compounds on siliconeimpregnated paper. J. Biol. Chem. 234:672-676.

18. Lester, R. L., D. C. White, and S. L. Smith. 1964. The 2-desmethyl vitamin $\mathrm{K}_{2}$ 's. A new group of naphthoquinones isolated from Haemophilus parainfluenzae. Biochemistry 3:949-954. 
19. Pittman, M. 1957. Genus IV: Haemophilus, p. 406-413. In R. S. Breed, R. G. E. Murray, and N. R. Smith (ed.), Bergey's manual of determinative bacteriology, 7 th ed. William \& Wilkins Co., Baltimore.

20. Reyn, A., A. Birch-Anderson, and S. P. Lapage. 1966. An electron microscope study of thin sections of Haemophilus vaginalis (Giardner and Dukes) and some possibly related species. Can. J. Microbiol. 12:1125-1136.

21. Smith, L. 1968. The respiratory chain system in bacteria, p. 55-122. In T. P. Singer (ed.), Biological oxidations. Interscience Publishers, New York.

22. Szarkowska, L., and M. Klingenberg. 1963. On the role of ubiquinone in mitochondria. Spectrophotometric and chemical measurements of its redox reaction. Biochem. Z. 338:674-697.

23. Whistance, G. R., J. F. Dillon, and D. R. Threlfall. 1969. The nature, intergeneric distribution and biosynthesis of isoprenoid quinones and phenols in Gram-negative bacteria. Biochem. J. 111:461-472.
24. Whistance, G. R., and D. R. Threlfall. 1968. Effect of anaerobiosis on the concentrations of demethyl. menaquinone, menaquinone and ubiquinone in Escherichia freundii, Proteus mirabilis and Aeromonas punctata. Biochem. J. 108:505-507.

25. White, D. C. 1965. The function of 2-desmethyl vitamin $\mathrm{K}_{2}$ in the electron transport system of Haemophilus parainfluenzae. J. Biol. Chem. 240:1387-1394.

26. White, D. C. 1966. The obligatory involvement of the electron transport system in the catabolic metabolism of Haemophilus parainfluenzae. Antonie van Leeuwenhoek J. Microbiol. Serol. 32:139-158.

27. White, D. C., and L. Smith. 1962. Hematin enzymes of Haemophilus parainfluenzae. J. Biol. Chem. 237:1332-1336.

28. Zinnemann, K., and G. C. Turner. 1963. The taxonomic position of 'Haemophilus vaginalis' (Corynebacterium vaginale). J. Pathol. Bacteriol. 85:213-219. 